\title{
MASA syndrome
}

INSERM

\section{Source}

INSERM. (1999). Orphanet: an online rare disease and orphan drug data base. MASA syndrome. ORPHA:2466

MASA syndrome (Mental retardation, Aphasia, Spastic paraplegia, Adducted thumbs) is a historical term used to describe a phenotype now considered to be part of the X-linked L1 clinical spectrum (L1 syndrome, see this term). MASA is characterized by mild to moderate intellectual deficit, delayed development of speech, hypotonia progressing to spasticity or spastic paraplegia, adducted thumbs, and mild to moderate distension of the cerebral ventricles. 